\title{
INTRODUCTION TO GUEST EDITORS
}

\section{Scott L. Spear, M.D., F.A.C.S. and Steven P. Davison, M.D., D.D.S., F.A.C.S.}

$\mathrm{I}_{\mathrm{t}}$ is our good fortune to have Dr. Scott Spear and Dr. Steven Davison as guest editors for this edition of Seminars in Plastic Surgery on the topic of "New Trends in Reduction and Mastopexy." I want to thank Drs. Spear and Davison personally for this outstanding edition and express my sincere thanks to all authors for their contributions. Dr. Spear is well known for his contributions in the field of breast reconstruction using implants as well as flaps.

Dr. Spear received his medical degree from the University of Chicago and completed his general surgery residency at Beth Israel Hospital in Boston under Harvard Medical School in 1978 and completed his plastic surgery residency at the University of Miami in 1980. In addition Dr. Spear completed a Craniofacial Fellowship at L'Hospital Enfants Malades in Paris, France in 1980.

Since 1992, Dr. Spear has been Chief of the Division of Plastic and Reconstructive Surgery at Georgetown University School of Medicine in Washington, D.C., and is Director of The Georgetown University Hospital Training Program in Plastic Surgery. $\mathrm{He}$ is an active member of many medical societies and has been engaged in scholarly writing from the beginning of his career, authoring over 85 articles in peer-reviewed journals and authoring numerous chapters on breast reconstruction. We are proud to say that he serves on the editorial board of Seminars in Plastic Surgery. Dr. Spear's devotion to his profession as an educator and clinician are well known in the plastic surgery community.

Prior to going into plastic surgery, Dr. Davison completed dental school and obtained a residency in prosthodontics in 1987; he went on to complete a fellowship in maxillofacial prosthodontics and dental oncology at M.D. Anderson Hospital in 1988.

Dr. Davison obtained his medical degree from the University of Maryland in 1992. He completed a residency in otolaryngology at Mayo Graduate School of Medicine in 1997 and a plastic surgery residency at the University of Pittsburgh in 1999.

$\mathrm{He}$ is board certified in otolaryngology, plastic surgery, and facial plastic surgery. Dr. Davison began his affiliation with the Georgetown University Medical Center in 1999 and currently holds the post of Assistant Professor in the Division of Plastic Surgery at Georgetown. His interests in breast surgery are breast reduction and microsurgical breast reconstruction. At this early stage in his career he has authored numerous publications and is an active member of several plastic surgery societies.

Saleh M. Shenaq, M.D Editor in Chief ${ }^{1}$

New Trends in Reduction and Mastopexy; Editor in Chief, Saleh M. Shenaq, M.D.; Guest Editors, Scott L. Spear, M.D., F.A.C.S. and Steven P. Davison, M.D., D.D.S., F.A.C.S. Seminars in Plastic Surgery, Volume 18, Number 3, 2004. Address for correspondence and reprint requests: Saleh M. Shenaq, M.D., Department of Plastic Surgery, Baylor College of Medicine, 6560 Fannin, Suite 800, Houston, TX 77030. ${ }^{1}$ Department of Plastic Surgery, Baylor College of Medicine, Houston, TX. Copyright (C) 2004 by Thieme Medical Publishers, Inc., 333 Seventh Avenue, New York, NY 10001 USA. Tel: +1(212) 584-4662. 1535-2188,p;2004,18,03,175,175,ftx,en;sps00123x. 